\section{Intravenous midazolam dose ranges in older patients sedated for oral surgery - a preliminary retrospective cohort study}

\author{
M. Chauhan, ${ }^{* 1}$ E. Carter ${ }^{1}$ and P. Rood ${ }^{1}$
}
IN BRIEF
- Reveals a relationship between age and range of doses of midazolam expected when sedating patients for dental patients by titration.
- Informs practice in the sedation of older patients for dental procedures.
- Advocates the use of a titration method for dental sedation.
- Demonstrates the need for further evidence to inform guidance on sedation of older patients.

Aim The aim of this study was to investigate differences in the titrated midazolam doses in older patients undergoing oral surgery procedures under intravenous sedation. Method The records of 50 patients aged 40-92 years who had undergone oral surgery procedures under intravenous sedation at Kings College Hospital between May 2008 and February 2009 were selected at random in each of the age groups: 40,50,60, 70 or $80+$. Results The mean dose for patients over the age of $70(2.8 \mathrm{mg})$ was 50\% less than the mean dose for those under the age of 70 (5.7 mg). Conclusions Our study found a correlation between the age of the patient and the dose of midazolam required for sedation before oral surgery procedures, with, on average, older patients requiring less midazolam. A range of doses are required in any age group, but the range decreases as age increases.

\section{INTRODUCTION}

There is little published on dosage recommendations for dental sedation in older patients. The UK has an ageing population ${ }^{1}$ and people are retaining their teeth longer; the proportion of dentate adults over the age of 65 has increased approximately four-fold from 21\% in 1978 to 77\% in 2009 (Fig. 1).2,3 Six percent of adults aged 65-84 and 9\% of those aged 85 and over suffer from extreme dental anxiety. ${ }^{2}$ Oral surgery procedures can be moderately invasive and may indicate sedation to improve the patient experience. ${ }^{4}$ There are, therefore, more patients who are older and more who are dentate, potentially requiring intravenous sedation to allay anxiety during dental treatment. Older patients are known to be at greater risk of morbidity and mortality when presenting for surgery, ${ }^{5}$ so the importance of understanding the effect of sedation on the older patient cannot be underestimated.

Conscious sedation is defined by the Department of Health as; 'A technique in which the use of a drug or drugs produces a state of depression of the central nervous system (CNS) enabling treatment to be carried out, but during which verbal contact with the patient is maintained throughout

'Department of Oral Surgery, King's College Hospital NHS Foundation Trust, Bessemer Road, Denmark Hill, London, SE5 9RS

${ }^{*}$ Correspondence to: Mr Mahesh Max Chauhan Email:max.chauhan@nhs.net

Online article number E12

Refereed Paper - accepted 9 October 2013

DOI: 10.1038/sj.bdj.2014.197

${ }^{\circ}$ British Dental Journal 2014; 216: E12

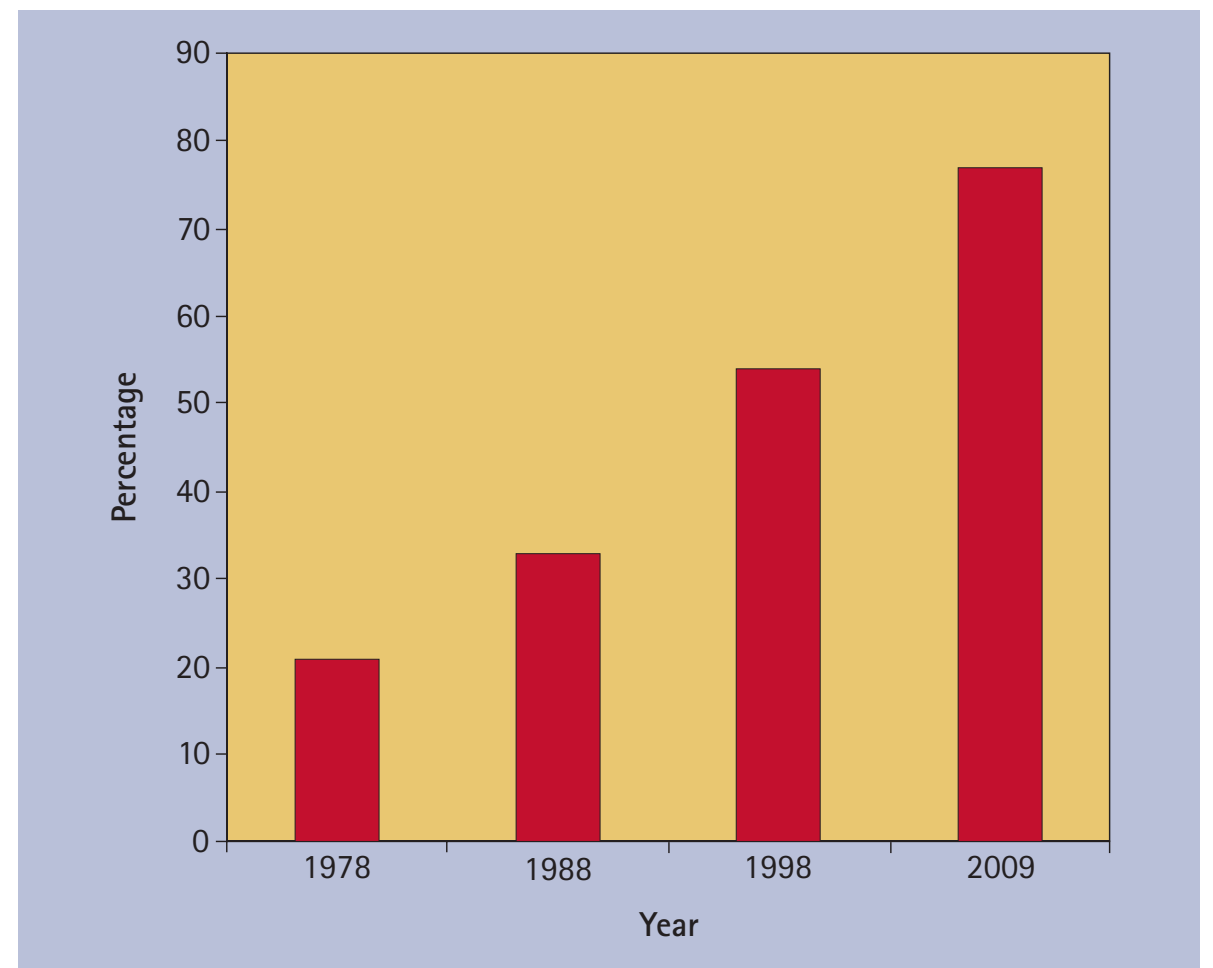

Fig. 1 Percentage of population over 65 years old who are dentate

the period of sedation. The drugs and techniques used to provide conscious sedation for dental treatment should carry a margin of safety wide enough to render loss of consciousness unlikely'; ${ }^{6}$ a definition supported by the General Dental Council. ${ }^{7}$ In routine intravenous dental sedation the required level of conscious sedation is reached by titration, usually with midazolam. If the same drug is given as a bolus dose it may induce unconsciousness. ${ }^{6,7}$
Older patients are known to have altered responses to many drugs as a result of their progressive decline in systemic physiology. ${ }^{8}$ Midazolam is water-soluble and as older patients have a decrease in total body water content this could result in a relatively higher dose being administered. Older patients also have reduced cardiac output, resulting in decreased hepatic and renal perfusion leading to slower removal of the drug from the body, hence a lower initial dose being required. 
Although not in the context of oral surgery procedures, some literature has been published on conscious sedation using midazolam in older patients. Bell et al. found a significant relationship between the dose of midazolam required using titration and the age of the patient. In 800 patients only $7.2 \%$ of those aged over 70 years required more than $5 \mathrm{mg}$ of midazolam, compared to $83 \%$ of patients below the age of 70 years. ${ }^{9}$ The elimination half-life of midazolam has been found to be significantly prolonged and total clearance of the drug significantly reduced in older males compared to young males, though interestingly no significant difference was found in females. ${ }^{10}$ Ageing increases the pharmacodynamic sensitivity to the hypnotic effects of midazolam independent of the pharmacokinetics of the patient. ${ }^{11}$ This suggests that the changes in water content and excretion of midazolam are not the only source of the altered action of midazolam in the older patient, but that they are also more sensitive to the drug.

Older patients also have more difficulty in achieving stability on movement following conscious sedation, ${ }^{12}$ therefore must be adequately assessed following sedation before discharge, especially considering the consequences of falls in this group of patients. Pathology can also change the manner in which midazolam affects the older patient. Pre-operative assessment of any patient is vital when providing treatment with sedation, and older patients inevitably are more likely to suffer from co-morbidities, with most older patients being ASA grade 2 or higher. ${ }^{5}$ Medical problems in older people are most commonly cardiovascular, ${ }^{5}$ respiratory and endocrine, with hypertension, heart failure, dysrhythmias, COPD and diabetes frequently seen. Medications for these conditions need to be considered for their possible impact on the active concentration of midazolam, as many drugs can affect the sedative and hypotensive effect of midazolam, including very commonly prescribed drugs such as betablockers, calcium channel blockers, nitrates, diuretics, ACE inhibitors and some antifungal, antiviral and antibiotic drugs. ${ }^{13}$

\section{Guidance for sedation in the older patient}

The National Patient Safety Agency (NPSA) Rapid response repor $t^{14}$ published in December 2008 reported 498 patient safety incidents relating to inappropriate dose or administration of midazolam, including three deaths over a four year period. The report recommended a change in the concentration of midazolam used from $10 \mathrm{mg}$ in $5 \mathrm{ml}$ to $1 \mathrm{mg}$ in $1 \mathrm{ml}$ and supported the recommendations of the National Confidential Enquiry into Patient
Outcome and Death (NCEPOD), ${ }^{15}$ which states that in patients over 70 years of age:

- Maximum of $2 \mathrm{mg}$ to be drawn up at any one time

- Maximum dose of $2 \mathrm{mg}$ (although occasionally exceeding this may be appropriate)

- Single bolus dose should not be administered

- Maximum dose of midazolam (mg/ $\mathrm{kg}$ ) should be halved and given in increments, until the desired effect is achieved.

The British Society of Gastroenterology published guidelines in 2003, recommending that older patients 'are given 1 to $2 \mathrm{mg}$ initially with a sensible pause to observe effect. ${ }^{16}$ The British National Formulary (BNF) states that midazolam should be administered by slow IV injection initially of $0.5-1 \mathrm{mg}$ in elderly patients, followed by titrating if necessary in steps of $0.5-1 \mathrm{mg}$ up to a maximum dose of $3.5 \mathrm{mg} .{ }^{13}$ Craig and Skelly state that in those over 65 years of age $1 \mathrm{mg}$ should be administered over 30 seconds, then pause for four minutes before continuing with $0.5 \mathrm{mg}$ increments every two minutes if required.$^{17}$ Furthermore they say that in this older group often only $2 \mathrm{mg}$ will be required for adequate sedation.

\section{AIM}

The aim of this study was to investigate differences between the titrated midazolam doses in older patients undergoing oral surgery procedures under intravenous sedation.

\section{OBJECTIVES}

To quantify the difference in dosage of intravenous midazolam between the under 70 and over 70 age groups and to make recommendations for the treatment of older patients who are undergoing intravenous dental sedation with midazolam.

\section{METHOD}

The records of 50 patients aged 40-92 years that had undergone oral surgery procedures under intravenous sedation at Kings College Hospital, Denmark Hill, London were selected at random in each of the age groups: 40,50 , 60,70 or $80+$ (this group had an upper age of 92). Information from the notes was recorded in a proforma before being transferred to a spreadsheet for analysis. The information was collected from the 'Record of oral surgery procedure' booklet and 'Medical history form' contained in the patients' case notes. This included the patient's gender, age, drug history, ASA grading, blood pressure, pulse, oxygen saturations and midazolam dose (in milligrams).

The surgical staff providing care for the patients ranged from supervised undergraduates to consultants. All midazolam used was drawn up from $10 \mathrm{mg}$ in $5 \mathrm{ml}$ vials of aqueous solution for injection, not $1 \mathrm{mg}$ in $1 \mathrm{ml}$, as this treatment was carried out before the NPSA Rapid response report recommendations. ${ }^{14}$ Teaching on sedation within the hospital is to titrate midazolam against patient response, starting with $2 \mathrm{mg}$ initially over 30 seconds, wait two minutes, then $1 \mathrm{mg}$ every 30 seconds; and in patients who are older than 65 (or have significant medical history) $1 \mathrm{mg}$ initially over one minute, wait three minutes, followed by $0.5 \mathrm{mg}$ every minute.

\section{RESULTS}

Of the 50 patients whose notes were reviewed 29 were female (58\%) and 21 were male (42\%). The age range was from 40 to 92 years, and the mean age was 60 years at the time of treatment. All patients had their treatment carried out between 14 May 2008 and 26 February 2009.

\section{Relevant medical history and drug history}

Thirty-seven patients (74\%) had recorded medical problems. These were mainly cardiovascular and respiratory. Nineteen patients (38\%) had hypertension, the majority of these were over 60 years old. Thirty-five patients (70\%) were on medication. It was found there was an increase in the proportion of ASA 2 patients over the age of 50 (Fig. 2).

\section{Dose of midazolam}

In each of the age groups both the mean the doses of midazolam and, more interestingly, the range of doses within that given group, decreased as age increased (Fig. 3). The trend of decreasing mean dose was analysed using an anova comparison of means and was found to be statistically significant ( $p<0.001$ ). The mean dose for patients over the age of $70(2.8 \mathrm{mg})$ was $50 \%$ less than the mean dose for those under the age of $70(5.7 \mathrm{mg})$.

The $2 \mathrm{mg}$ NPSA recommended maximum dose was exceeded in 50\% of patients over the age of 70 , and $30 \%$ exceeded the BNF's maximum dose of $3.5 \mathrm{mg}$, with no significant problems relating to the sedation recorded. No adverse outcomes were recorded in any patients.

\section{DISCUSSION}

This preliminary retrospective case note review was carried out to identify trends in 


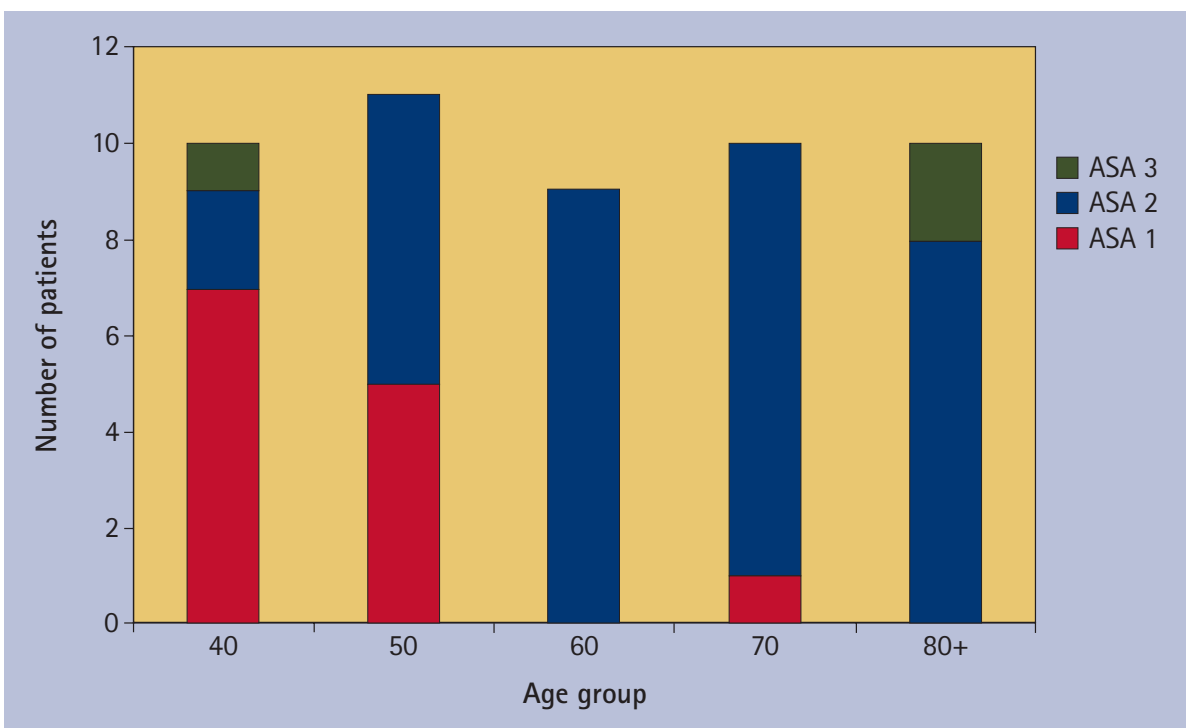

Fig. 2 ASA gradings of the different age groups

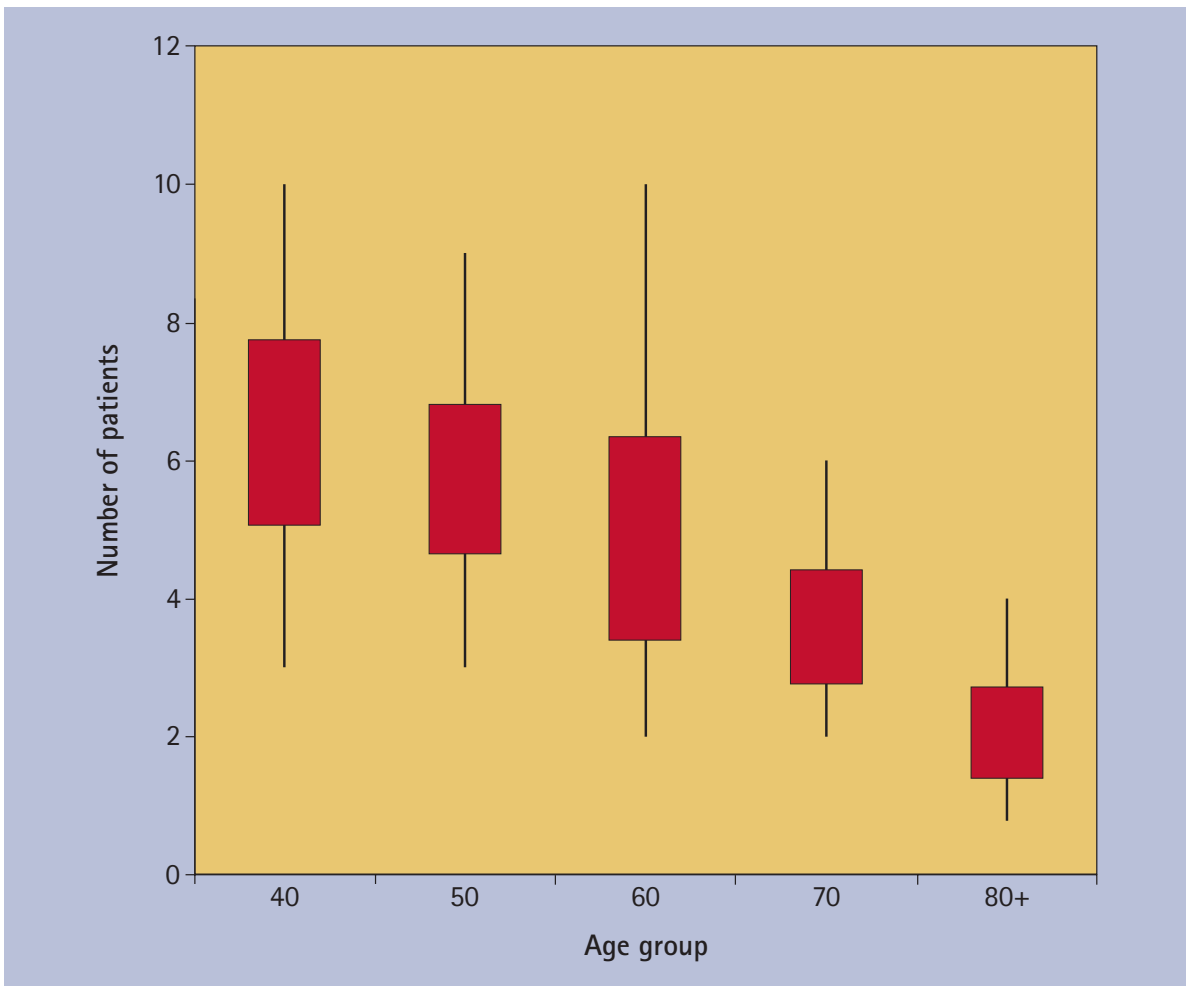

Fig. 3 Range of doses and 95\% confidence intervals by age group

dose of midazolam given to patients in a wide age range of 40-92 years, thus allowing comparison of younger and older patients. Our study found a correlation between the age of the patient and the dose of midazolam required for sedation before oral surgery procedures, with, on average, older patients requiring less midazolam. These findings mirror the study by Bell et al. ${ }^{9}$ examining midazolam sedation for patients undergoing upper gastrointestinal endoscopies. A key finding was that each successive age group required a reduced range of doses with each successive group of increasing age. This has not previously been reported in the literature. This needs further investigation, as the range administering midazolam to older patients and may be used to improve evidence-based guidelines on dosing regimens.

The NPSA also state that flumazenil administration is known to be associated with a higher mortality rate $^{14}$ and the occurrence of a critical event such as hypoxia. ${ }^{18}$ In the patients included in our cohort flumazenil was not administered. As midazolam can be safely administered to older patients they should be able to benefit from the same quality of care that sedation can provide, and it should therefore not be withheld on account of age.

\section{CONCLUSIONS}

Although the study was small the results were clear:

- Titrating the dose of midazolam to the patient's response is safe and effective in patients over 70 years old, provided the modified technique described is used

- A range of doses will be required in any age group but that the range decreases as the age increases

- The trend for increasing ASA with age was confirmed: therefore a larger study is planned to allow analysis of other factors that could influence outcomes - such as weight, co-morbidities and medications.

In memory of the late Dr Derek Debuse - Project Supervisor, Guy's Hospital.

We would like to thank the following people for the invaluable support they have given throughout this project: Dr David Craig - Consultant and Head of Sedation and Special Care Dentistry, Guy's Hospital; Ms Clare Walker (Brown) Specialist Dental Nurse, Guy's Hospital - nurse; Ms Lisa Olliffe Dental Service Manager, King's College London - case notes; Ms Shruti Gurung - Student Dental Nurse, King's College London - data entry; Dr Salma Ayis - Lecturer in Medical Statistics, King's College London - statistical support

1. Bayliss J, Sly F. Ageing across the UK. Regional trends 42. Newport: Office for National Statistics, 2010.

2. The Health and Social Care Information Centre. Adult Dental Health Survey 2009 - first release. London HSCIC, 2010.

3. Office for National Statistics. Adult Dental Health Survey - oral health in the United Kingdom 1998. London: ONS, 1999.

4. Coulthard P, Bridgman C M, Gough L, Longman L, Pretty I A, Jenner T. Estimating the need for dental sedation. 1. The Indicator of Sedation Need (IOSN) a novel assessment tool. Br Dent J 2011; 211: E10.

5. The Association of Anaesthetists of Great Britain and Ireland. Anaesthesia and peri-operative care of the elderly. London: AAGBI, 2001.

6. Department of Health. A conscious decision - a review of the use of general anaesthesia and conscious sedation in primary dental care. London: DH, 2000.

7. General Dental Council. Standards for dental professionals. London: GDC, 2005.

8. Miller R D. Anaesthesia for the elderly. In Miller R D (ed) Anaesthesia. pp 1231-1246. New York: Churchill Livingstone, 1981.

9. Bell G D, Spickett G P, Reeve P A, Morden A, Logan $R$ F. Intravenous midazolam for upper gastrointestinal endoscopy: A study of 800 consecutive cases relating dose to age and sex of a patient. Br J Clin Pharmacol 1987; 23: 241-243. 


\section{RESEARCH}

10. Greenblatt D J, Abernethy D R, Locniskar A, Harmatz J S, Limjuco R A, Shader R I. Effect of age, gender and obesity on midazolam kinetics. Anaesthesiology 1984; 61: 27-35

11. Jacobs JR, Reves J G, Marty J, White W D, Bai S A, Smith LR. Ageing increases pharmacodynamic sensitivity to the hypnotic effects of midazolam. Anesth Analg 1995; 80: 143-148.

12. Fujisawa T, Suzuki S, Tanaka K, Kamekura N,

Fukushima K, Kemmotsu 0. Recovery of postural stability following conscious sedation with midazolam in the elderly. J Anesth 2002; 16: 198-202.
13. Joint Formulary Committee. British National Formulary (online). London: BMJ Group and Pharmaceutical Press.

14. NHS National Patient Safety Agency. Rapid response report: reducing risk of overdose with midazolam injection in adults. NPSA 2008. Online report available at http://www. nrls.npsa.nhs.uk/EasySiteWeb/getresource. axd?AssetID=60300\&type=full\&t.. (accessed October 2013)

15. National Confidential Enquiry into Patient Outcome and Death. Scoping our practice. London: NCEPOD,
2004.

16. British Society of Gastroenterology. Recommendations for standards of sedation and patient monitoring during gastrointestinal endoscopy. London: Endoscopy Section Committee Working Party, 2003.

17. Craig D, Skelly M. Practical conscious sedation. London: Quintessence Publishing, 2004.

18. Lord D A, Bell G D, Grey A et al. Sedation for gastroentestinal endoscopic procedures in the elderly: getting safer but still not nearly safe enough. London: British Society of Gastroenterology, 2006. 